\title{
Constructive Alignment in Economics Teaching: A Reflection on Effective Implementation
}

Dr Michael McCann

Nottingham Business School

Nottingham Trent University

50 Shakespeare Street

Nottingham

NG1 4FQ

Tel: $+44(0) 1158482451$

Email: michael.mccann@ntu.ac.uk

\begin{abstract}
The typical approach to student-centred learning in Economics has focused on innovation within the classroom, with little thought given to how this complements teaching and learning and, crucially, assessment. This paper reflects on the implementation of constructive alignment in a final year managerial economics course. It demonstrates how it is possible to design coursework assessment for economics which both encourages constructivist learning, while also limiting the potential for plagiarism. The successful assessment allows students' autonomy in selecting what evidence matches the assessment requirements. Further, the teaching, learning and formative assessment activities recommended are crafted to directly align with the requirements of the summative assessment. This structured alignment process, by providing repeated formal and informal feedback, produces levels of student engagement and reflection that facilitates deeper learning.
\end{abstract}

Key Words: Constructive alignment, Economics, Critical reflection, Student Engagement 


\section{Introduction}

Constructive alignment has become in recent years a prominent feature of any discussion about effective teaching and learning in higher education. Its proponents argue that learning is enhanced by making learning activity central to a learners' creation of meaning (Biggs 1996; Healey and Jenkins 2000; Kolb and Kolb 2005). This approach regards learning as a process through which knowledge is 'constructed' by the student. "Knowledge is obtained and understanding is expanded through active construction and reconstruction of mental frameworks" (Killen 2007: 7). Further, it is argued that an appropriate alignment of teaching, learning and assessment provides the incentive and structure to facilitate deeper learning by students.

The origins of constructive alignment and its adoption lie in reflections upon the changing nature of the student population in higher education across many countries. It is found that as an increasing proportion of school leavers pursue bachelor degree courses, many choose their discipline not out of curiosity about a subject area, but because they feel they need a degree to enhance their employment prospects. There is a concern that such students only want to put in sufficient effort to pass a subject and so adopt what Marton and Säljö (1976) term a 'surface' approach to learning. According to Biggs (1999), the teaching challenge is to encourage such students to change their mind-set and approach and to become 'deeper learners' (see figure 1).

The constructive alignment approach has been adopted in a variety of disciplines with great success. More active participation by learners has been variously reported as a result of its implementation (Cohen 1987; Tynjala, 1998; Walsh, 2007; Szili and Sobels 2011). Some of the successful applications reported have been on courses with a more explicit vocational underpinning or work-based element. On such courses the core mechanisms of constructive alignment, involving ongoing reflections on repeated tasks to enhance knowledge and skills through experiential learning, seem appropriate. 
Figure 1: Student orientation, learning styles and depth of learning

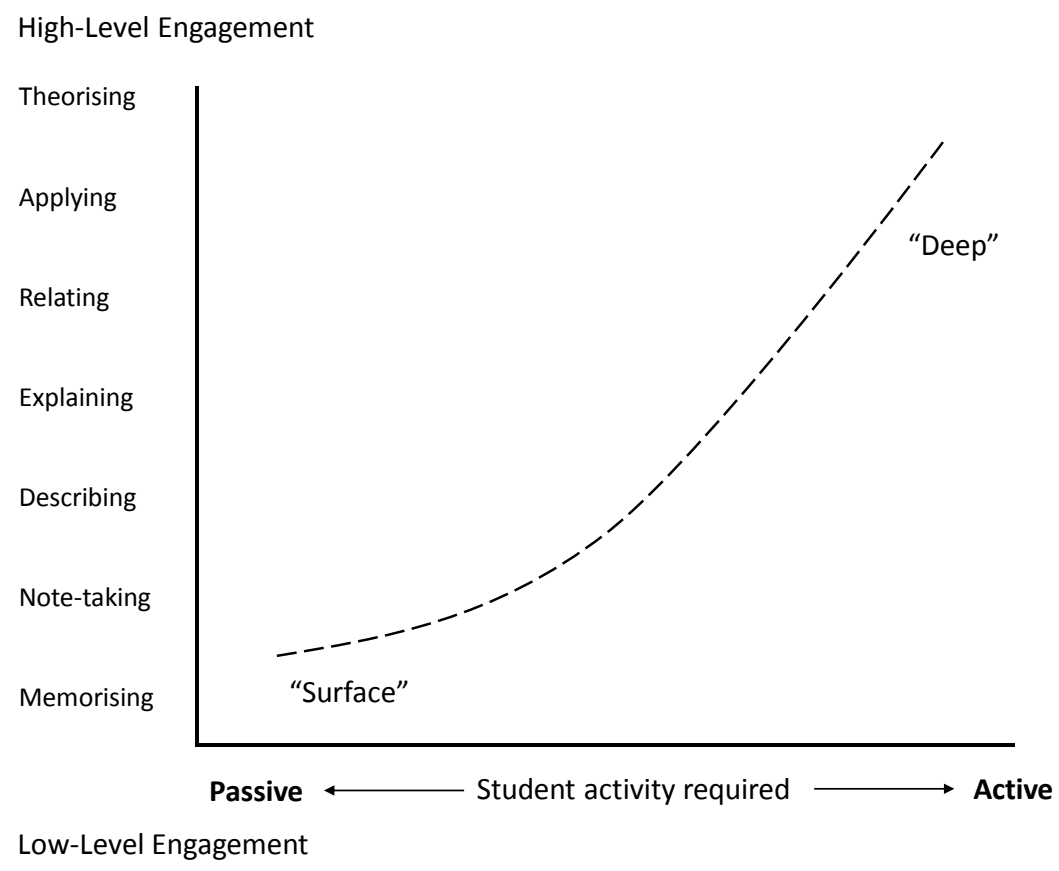

However, in economics education there has been limited adoption (Chen and Line, 2012; Roach, 2014). This is due to concerns about the different inculcation, development and application of economic principles, compared to vocational subjects. In economics students do not practise a vocational skill-set. Rather, they apply economic knowledge and skills in an analytical manner, in most instances as 'outside' observers (Wilson and Dixon, 2009). However, it is also within economics learning that student engagement and the facilitation of deeper learning are key problems (Forsythe, 2002).

This paper reflects upon the implementation of constructive alignment within a final year course in managerial economics. During this process it addresses two questions commonly raised in economics teaching in higher education. Firstly, it reviews how coursework assessment design can be used as an effective vehicle for constructive learning in economics while also addressing concerns raised about the reliability of un-invigilated coursework assessment. It also examines how this can be aligned with teaching and learning in order to stimulate deeper learning. Our conclusions demonstrate that an un-invigilated coursework 
assessment can facilitate learning in ways which stimulate higher cognitive thinking. Effective design can also discourage poor scholarship and plagiarism when mechanisms are employed which not only reduce the incentive for poor scholarship and plagiarism, but also make it easier to spot. Crucially, a clear link must be traced from teaching and learning activities (including formative assessments) to the summative assessment to ensure that formal and informal feedback is perceived to be valuable. This repeated signalling of the link between feedback from learning activities and assessment is, we conclude, important in facilitating deeper learning.

\section{Evidence for Reflection and Evaluation}

A variety of evidential sources have been adopted to facilitate reflection and evaluation of the implementation of constructive alignment. Quantitative evaluation is difficult to achieve since, due to the range of variables involved over the four years of implementation which form the basis of this review, it is difficult to establish and measure cause and effect relationships. Consequently, in reflecting on the effectiveness of the implementation, a predominantly qualitative approach is adopted. The sources of evidence are described below:

- Measures of course engagement and performance - attendance rates, participation rates in formative assessments and performance in summative assessment using UK degree classifications.

- Course Reviews - As part of the University's quality processes, annual course reviews are conducted. The review involves teaching staff. The review encompasses students' feedback, the external examiner's comments, students' performance and the teaching team's reflections. This review culminates in a written report. Indeed, many of the iterative developments reported in the paper are the outcome of this review. 
- External Examiner's comments - The course is assigned an external examiner who has expertise in the academic area. The examiner reviews the teaching, learning and assessment on a course each year. The teaching team meet with the external examiner at the time of the subject assessment board and this is followed up by a written report. The implementation of constructive alignment coincided with the appointment of a new one in 2012. Hence, the same external examiner has been in place throughout the period under review. Evidence from the external examiner is limited, since his written report is exception-based. Where appropriate, we include exception reporting which relates to the managerial economics course.

- Students' Feedback - Formal student feedback for the course is provided through standardised forms, completed $3 / 4$ of the way through the year-long course. The form has two sections, a quantitative section with a selection of statements linked to a Likert scale, and a qualitative section that allows for free text comments. Over the years, between 60 $80 \%$ of students have completed the course evaluation, which is a good proportion of the total population from which to draw conclusions. The use of student feedback for pedagogic research raises some ethical issues relating to 'informed consent' as well as the confidentiality, security and retention of this data. We have gained ethical approval for the use of this data for the research.

We discuss the relevant outcomes of evaluation in relation to each aspect of the implementation.

\section{Context}

Managerial economics involves the application of economic concepts and theories to decisionmaking in a corporate environment. The course subject for reflection in this paper is one offered in the final year of an undergraduate programme and centres on strategic decision-making. In 
the programme students are introduced to decision-making connected to themes of business expansion, restructuring and refocusing of corporate activities. Students learn skills which demonstrate a high level of critical thinking academic skills (application, analysis and evaluation). For a number of years this course was assessed with a mixture of group coursework and individually-written examination - with the examination given a significantly greater weighting. In 2012, as part of an institutional-wide curriculum review, the number of summative assessments completed by students was reduced. This resulted in some courses, including the one subject to this reflection, having only one summative assessment point.

Under the pre-2012 assessment regime, the performance of students in the unseen examination was relatively weak. Despite the design of questions and marking criteria which tried to elicit higher cognitive outcomes, students were being foiled by the nature of the preparation they undertook - rote learning, question-spotting, going through past papers - and the resource-limits they faced while completing the examination (Bridges et al., 2002).

Since, assessment is the crux of students' efforts on a course (Ramsden, 1992), the challenge for the teaching team was to design a method of assessment which would appropriately align with the desired learning outcomes of the course, while stimulating deeper engagement. This prompted a thorough review of the course, since by changing the assessment, there would be a need to modify the teaching and learning according to the principles of constructivism.

\section{Facilitating Engagement through Assessment Design}

Brown, Bull and Pendlebury (1997: 7) propose that; "if you want to change student learning then change the methods of assessment". The revised coursework assessment design is underpinned by the principles of constructivism in order to address all learning outcomes and 
promote a quality learning experience. The specific assignment brief requires the analysis of a variety of aspects of managerial decision-making in a specific corporate environment by applying relevant economic concepts and theories. Figure 2 shows an excerpt from the brief that illustrates the aspects being analysed.

\section{Figure 2: Excerpt from Assessment Brief}

You have been recently appointed as an economic consultant. You have been asked to conduct an economic analysis of the growth and development of a company chosen by yourself drawing on your training as a business economist.

The title of your report should be in the following form:

\section{'An economic analysis of the growth and development of (insert name of chosen company)'}

As part of the analysis, you should address the following aspects:

- Entrepreneurship and the birth of the firm

- Explanations for the growth of the firm including horizontal integration, vertical integration and diversification

- The investment strategies adopted: mergers, acquisitions, franchising, strategic alliances and corporate restructuring

- Developing and sustaining competitive advantage

- Corporate structure and governance

In order to facilitate deeper engagement, the design incorporates a number of features which also address concerns regarding scholarship levelled at un-invigilated coursework assessments. Students are given autonomy over aspects of the project which should encourage deeper, more active engagement in learning throughout the course. Firstly, students identify and analyse a unique company (on a first-come, first-serve basis). This means that each student has an exclusive perspective to bring to discussions on particular aspects of decision-making. Better scholarship is encouraged, as a student's individual and specific discussion about their selected company can be validated (Biggs, 1999). Secondly, students are given autonomy in choosing 
the evidence they use to demonstrate their learning. They critically apply theory to this evidence themselves (with guidance and feedback) and so evaluate their subject company's strategic decision-making. This discretion empowers students to construct their learning through their research and analysis of data in search of better performance. Thirdly, since the application of theory to companies will be different, there will be less scope for plagiarism. For instance, when analysing sources of competitive advantage, the combinations of industry and firm-specific factors will be different across companies. Therefore, copying the analysis of another student will not help achieve a better outcome.

Over the period that the new assessment regime has been used, student feedback suggests that they respond to the assessment design in the way anticipated according to the principles of constructive alignment. In the second section of the course feedback form, many free text comments imply that students appreciate the autonomy they are given in their learning through the nature of the assignment. Here are two examples of the type of comments:

"Like ability to choose own subject company"

"The coursework needed to search data from real companies."

When asked about which aspects of the course they really enjoyed, student feedback suggest that the assessment design is stimulating a deeper level of thinking. Here are examples of typical responses:

"The coursework, very practical and involving."

"Interesting assessment project. An interesting in depth research project, which is something we can get our teeth into"

"The coursework is really interesting and stimulating" 
Phrases like 'practical and involving', and 'something we can get our teeth into' suggest that the project encourages immersion in the theory at a deeper level. This is consistent with Biggs (1999) propositions that such work, by giving responsibility to students for selecting at least some of the evidence they are going to use to demonstrate their learning, should stimulate a desire to engage with material at a higher cognitive level. Further reflections, reported in a number of course reports, highlighted that the practical, student-centred nature of the assessment facilitated deeper engagement by students. Finally, comments by the external examiner regarding the nature of the assessment design have been favourable, particularly in relation to its relevant, applied style.

\section{Feedback: The Aligning of Teaching, Learning and Assessment Activities}

Careful assessment design is necessary for fostering deeper learning, but it is not sufficient. Our experience demonstrates that a novel refinement through a process of backward induction from the anticipated final learning outcomes, through assessed tasks to teaching and learning activities, is an important condition for facilitating deeper learning in discursive subjects such

as economics (see figure 3). This aids students' development of the cognitive skills needed to complete the assignment to a higher level. 
Figure 3: Process of backward induction in Constructive Alignment

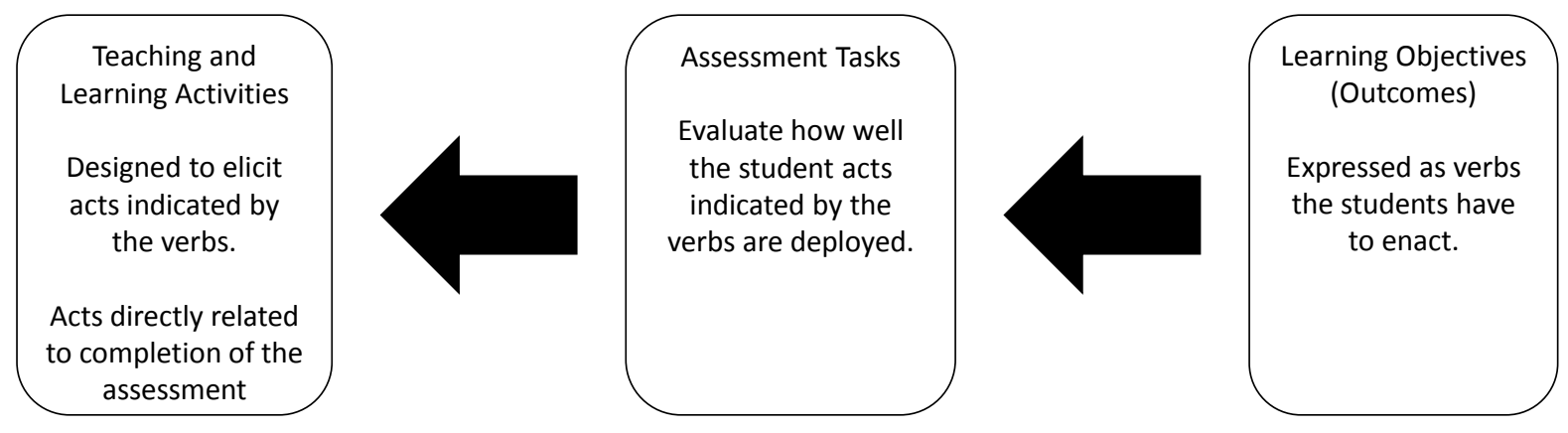

Developing a variety of activities during the course which provide both formal and informal feedback to students is a key requirement of fostering deeper learning. Evidence suggests that the provision of feedback has large and consistent positive effects (Black and William, 1998), but it has long been considered a weakness of pedagogy in higher education. Good practice requires feedback to be:

- $\quad$ Timely - feedback should be received early enough in the assessment process to be useful. It can be particularly useful to receive feedback during work-in-progress (Nicol and McFarlane-Dick, 2006).

- $\quad$ Specific - it must directly relate to the completion of the assignment, offering remedial advice.

- $\quad$ Ungraded - research suggests that comments accompanied by a poor grade of a workin-progress are unlikely to be used by students, since damage to self-esteem discourages them (Cooper, 2000). 
In the managerial economics course, there is a strong emphasis on the provision of both formal and informal feedback. A course schedule involves timely, specific and ungraded activities which provide both formal and informal feedback linked directly to the assessment.

These activities are signalled to students in the course handbook provided at the start of the course, clarifying students' expectations about feedback: They know when they will get it, what form it will take, and how it should be used. In course evaluation, between $80 \%$ and $100 \%$ of students have agreed that they receive regular feedback on their progress and that the feedback was timely. Across all of the academic years, $100 \%$ agree with the statement that feedback has identified areas that I can improve on in the future. These results suggest that the feedback provided is remedial, offering specific help to the completion of the assessment.

The clear course learning schedule, showing how activities relate to each other, is viewed positively. One question in the course evaluation questionnaire relates to course organisation, with $100 \%$ of students responding that the course is well-organised. Further, free text comments from students suggest they appreciate this clear structure. Here is an example:

"[Schedule]... clearly sets out when we will have coursework drop in sessions, assessments etc"

\section{Assessment Brief}

The assessment is distributed at the beginning of the course with an hour-long session devoted to explaining the brief. The brief includes assessment criteria which are linked directly to the learning objectives of the course. These relate to the quality of learning and demonstrate what has been learned and how well (Biggs and Tang, 2011). The criteria are:

Structure - Introduction, organisation, logical order of material, aims and conclusion

Research - Comprehensiveness, relevance and evidence of reading/research 
Argument - Coherence, fluency, critique and innovation

Presentation - Visual impact, grammar, spelling, legibility and referencing system

The briefing session which includes a detailed explanation of assessment criteria, is intended to indicate the standards that demonstrate higher cognitive processes. In addition, students have access to on-line examples of work completed by students from previous cohorts. These examples include high-, intermediate- and threshold-quality work to help explain the requirements for different standards.

The external examiner commended the use of such criteria, highlighting that this 'ex-ante' signalling clearly explains the standards demanded to achieve higher cognitive outcomes. Indeed, the examiner highlighted that such signalling is more important to students than written comments on submitted work at the end of a course, since it is timely and specific.

This signalling is appreciated by students. In the four years since the course redesign $100 \%$ of students who responded definitely agreed with the statement; assessment criteria were clearly explained. In addition, free text comments indicate that some students were further encouraged by having an understanding of the depth of learning expected if they wished to achieve higher grades. Here is one comment from 2014:

\section{"Feedback on way tutor marks is helpful"}

Staff on the course also reflected that the extensive briefing, taking place early in the course, “...encouraged students to begin their report early and continually work on it." (Course report, 2013). This type of comment is echoed in subsequent reports indicating that active engagement with the assessment at the beginning of the course provides students with the greatest opportunity to gradually immerse themselves more deeply in the applied analysis, improving the scope for reflective learning. 


\section{Alignment of Formal Formative Assessment}

As part of the alignment of course activities and assessment, formal formative assessments are used. Since participation in these assessments is voluntary, it is important to design these in a way to encourage their completion. Our experience indicates that one way to do this successfully is by linking the formative assessment tasks clearly with the requirements of the summative assignment. Such design increases the incentive for students to engage with the assessment, improving the potential for constructive self-reflection using the feedback provided (Nicol and McFarlane-Dick, 2006).

The first formal formative assessment requirement is a poster at the end of the first term. At this stage it is expected that students present some initial data on the areas they are intending to investigate, including any early themes they plan to analyse. This poster session provides an opportunity for students to gain experience in presenting information in a meaningful and accessible way, while also receiving guidance on their choice of data and analysis. Feedback is provided within two weeks, and reviews the choices students have made, providing them with additional suggestions about possible lines of inquiry. As part of continuous improvement, staff are responsive to ideas. In 2014 the external examiner suggested the incorporation of a peerreview process into the poster tours and this proposal was consequently incorporated. Students are placed in groups and discuss each other's poster informally, they then use a grading matrix to provide anonymous written feedback to each other. The opportunity to both give and receive feedback encourages a cross-fertilisation of ideas which stimulates the learning process further.

Further, formal formative assessment opportunities are available during the second term. Students can submit two drafts of their report for feedback on their analysis and the quality of the written arguments presented. Students are allowed some autonomy in deciding when to submit their drafts. 
Reflections by teaching staff have indicated an opinion that the design of the formative assessments act as disciplinary mechanisms to deter students from engaging in plagiarism. Firstly, the completion of formative assessments commit students to devote time and effort to do preparatory work (Cooper, 2000). Secondly, since teaching staff see examples of work throughout the course, it is easier to identify any substantial inconsistencies between formative and summative work submitted. Not only does this deter cheating by students 'ex-ante', it makes plagiarism easier to spot 'ex-post' (Gibbs and Simpson, 2004).

Table 1: Participation in Formative Assessments and Performance in Summative Assessment

\begin{tabular}{|l|c|c|c|c|}
\hline & $\mathbf{2 0 1 2 / 2 0 1 3}$ & $\mathbf{2 0 1 3 / 2 0 1 4}$ & $\mathbf{2 0 1 4 / 2 0 1 5}$ & $\mathbf{2 0 1 5 / 2 0 1 6}$ \\
\hline $\begin{array}{l}\text { Percentage Participating } \\
\text { in Formative assessment }\end{array}$ & $85 \%$ & $80 \%$ & $61 \%$ & $81 \%$ \\
\hline $\begin{array}{l}\text { Average Grade for } \\
\text { Participants }\end{array}$ & $\begin{array}{c}\text { Upper } \\
\text { Second }\end{array}$ & $\begin{array}{c}\text { Upper } \\
\text { Second }\end{array}$ & First & First \\
\hline $\begin{array}{l}\text { Average Grade for Non- } \\
\text { participants }\end{array}$ & Third & $\begin{array}{c}\text { Lower } \\
\text { Second }\end{array}$ & $\begin{array}{c}\text { Lower } \\
\text { Second }\end{array}$ & $\begin{array}{c}\text { Lower } \\
\text { Second }\end{array}$ \\
\hline
\end{tabular}

Since formal formative assessments are voluntary, an evaluation of the extent to which students value the feedback may be revealed by their willingness to participate in it. Table 1 shows participation rates among students as well as a comparison of the average grades of those who completed, and those who didn't complete, formative assessments. In general, participation rates are high, and suggest that more students look to learn at a deeper level, and reflect on the feedback they receive and develop the higher cognitive levels desired by the learning objectives of the course. The results indicate significantly higher average grades for those students who completed the formative assessment. This suggests that, in general, participation enables students to reflect on the feedback provided in order to develop their analysis of the chosen company and improve their outcomes. Indeed, staff have reflected that as their cumulative experience on the course has increased over time, they observe more examples of work and can 
recognise early the potential problems students may face. As a result, the quality of the tutors' feedback has become more focused, improving outcomes for all students who engage with the formative assessments. Tellingly, the average grade for those participating in the formal formative assessments has improved over time while the average for those who don't participate has remained a lower second.

These observations are supported by comments from students themselves. In general, they felt that the closely aligned formative feedback was useful, facilitating the deeper learning required to achieve qualitatively higher learning outcomes. Here is one comment from 2013 which reflects the general view:

"Lots of opportunity to get feedback, which means that I can see where I need to improve / study more."

\section{Informal Feedback through Teaching and Learning Activities}

In addition to formal feedback mechanisms, our reflections suggest that informal feedback from teaching and learning activities should be aligned with the summative assessment too, providing additional timely and specific informal feedback. In general, the type of activities should provide some guidance for students' research and analysis, prompting self-directed learning and reflection.

Sessions are integrated early in the course providing students with experience of using websites, databases and other resources to conduct research on their chosen company. This exposure means that all of the students can identify useful sources of information for their research and analysis in a timely manner, promoting equality of opportunity. While the guidance is specific, 
enabling students to source and retrieve relevant data for the analysis of their chosen companies, they must then be active in sourcing and retrieving the relevant data for themselves. It will not be done for them.

The majority of sessions focus on the theories, tools and techniques that students should utilise in analysing the different aspects of their company's decision-making. Over time teaching staff reflected that the best way of doing this was in a workshop-style 'flipped learning' environment. The emphasis is on interactive and collaborative learning through the application of theory, using problems, case studies, and videos as well as periodic informal discussions of company data presented by students relating to a particular aspect of analysis (Bergmann et al., 2012). See Figure 4 for an example of one of these exercises.

Figure 4: Example of Practice-based Activities

\section{Diversification}

Read the latest annual report of the company you have chosen for analysis.

Assess the degree of diversification by contribution to turnover:

- By product diversification

- By geographical diversification You find this in the company's annual report under segmentation analysis.

1) Use Rumelt's categorisation method

2) Use the Jacquemin and Berry measure

Prepare commentary on your findings for discussion in class.

The key point of such class activities is the practice of applying theory to 'real-world' decisions which are relevant to the assessment. They can use this experience to enhance their skills in preparation for completing the report. Consequently, students are more engaged, not only through the active learning environment, but as a result of the direct link between the class activities and the assessment. It is this comprehensive alignment which distinguishes our approach from much reported practice in economics education which emphasises 'performing' 
using interactive and participative learning techniques (Forsythe, 2002; Chen and Line 2012; Roach 2014). While studies suggest that such techniques do enhance engagement in economics teaching (Tsigaris, 2008: Van Wyk and Alexander, 2010), there is little evidence that they improve performance in assessment (Trigwell and Prosser, 2014). Our experience suggests that teaching and learning can be engaging, but the activities need to be aligned properly with assessment in order to stimulate deeper learning.

When commenting on teaching on the course, students recognise the link between teaching, learning and assessment, and used the interaction, the sharing of ideas and the practice in class to reflect on their learning. Here are several examples of comments that illustrate this view:

"I feel that the seminars are really good. Work relates to the coursework"

"Interaction in terms of sharing ideas with the group"

"Class activities made seminars worth going to"

"Applied to real-world examples and scenarios"

"Value use of case studies..."

"Interactive sessions, good opportunities to discuss topics..."

Finally, scheduled assessment clinics, integrated into the course work-scheme, enable students to discuss their individual report and receive feedback with their tutor on a one-to-one basis. This individual guidance encourages students to repeatedly review their knowledge of theory and practice, developing a more thorough analysis of their companies.

If students recognised that active involvement in class activities was a worthwhile experience, this would provide firm support for the use of informal feedback through teaching and learning activities. In the quantitative section of the course evaluation form, there are several statements which relate to this: The first one asks for a response to the following statement: 'I find the course intellectually stimulating'. One hundred percent of students agreed with this statement 
in both $2012 / 2013,2013 / 2014$ and $2015 / 2016$. The percentage was $81.8 \%$ in $2014 / 15$. The second statement was 'I find these classes valuable learning experiences'. Across the four academic years, one hundred percent of respondents either agreed or strongly agreed with this statement. Further, in responding to the question relating to things they did to help themselves learn, comments indicate the students regard as pivotal the role of the assessment in the course. In addition, feedback indicates that students recognised how continuing engagement with class activities enables the reflection and abstraction necessary for higher cognitive outcomes:

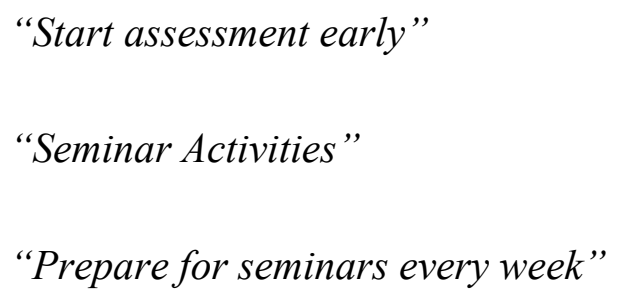

Such responses provide some evidence that students derive benefit from active participation in class activities. Another way of assessing how useful students find coming to class is by examining attendance. Figure 5 illustrates the pattern of median attendance at weekly classes over a period spanning from two years before the curriculum review to four years afterwards. These figures reveal a measure of revealed participation, and hence engagement. While one must be careful in drawing conclusions since there are several varying factors including the timing of classes and size and composition of student groups, the increasing trend shown in figure 5 suggest that attendance rates improved once teaching and learning became more directly aligned with assessment. 
Figure 5: Median attendance rates for course from 2010/2011 to 2015/2016

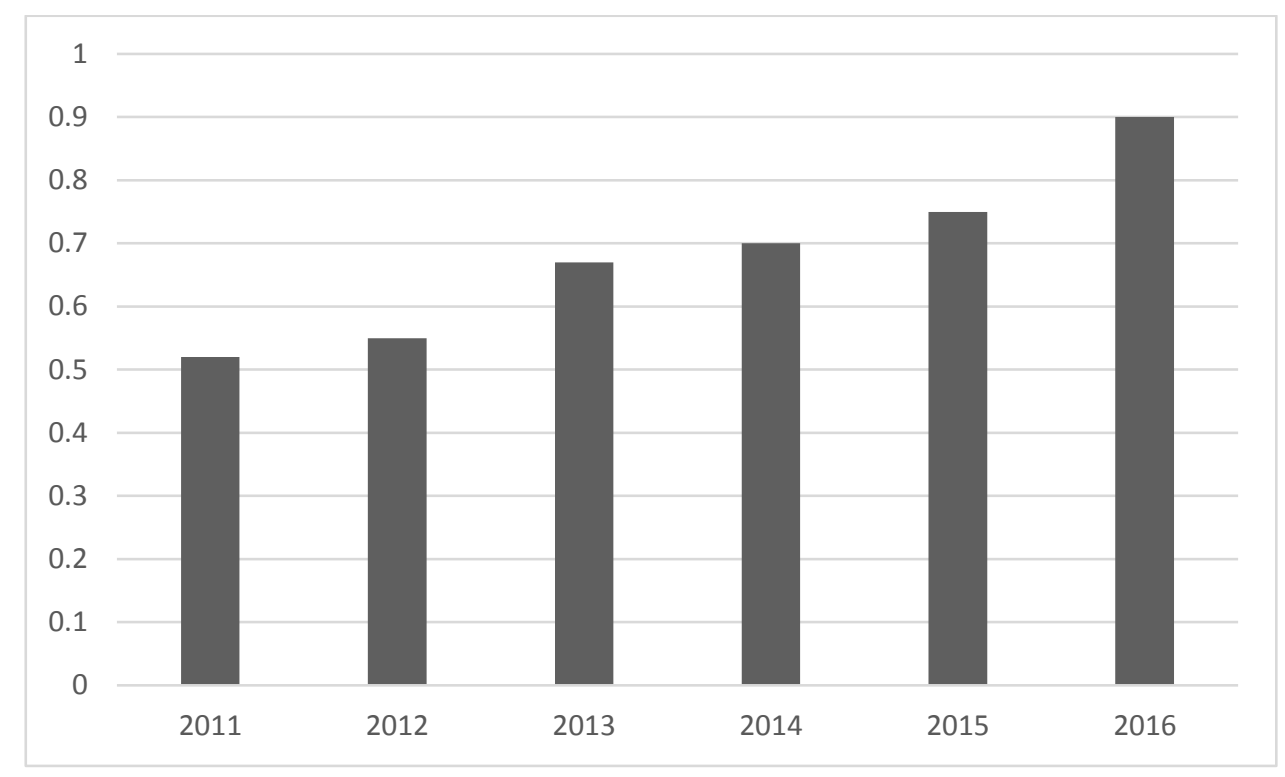

\section{Conclusion}

This paper reflects on the process of implementing constructive alignment in a final year managerial economics course. In addressing the questions which framed this reflection, it was found that careful assessment design of report-style coursework assessment can test students' ability to meet the course learning objectives, while also encouraging deeper engagement. The process can also be regarded as one that can help deter plagiarism. However, this is not sufficient, and a closely aligned programme of active teaching, learning and formative assessment activities is required. The key determining factor for success is the use of both formal and informal feedback mechanisms to encourage direct reflection of theories and their application in tasks useful for completing the written report. In this way, everything done throughout the course is orientated towards providing formal and informal feedback, stimulating deeper cognitive thinking. Staff reflection, external examiner's comments, student feedback, as well as participation and performance data, all suggest that this clear, signalled 
link does significantly improve the student experience, encouraging greater learner autonomy and active, deeper learning.

\section{References}

Bergmann, J. Overmyer, J and B. Willie 2012 The Flipped Class: What It Is and What It Is Not. Accessed on 25th May 2016. http://www.thedailyriff.com/articles/the-flipped-classconversation-689.php

Biggs, J 1996 Enhancing Teaching through Constructive Alignment, Higher Education, 32: 347-364.

Biggs, J. 1999 What the Student Does: Teaching for Enhanced Learning, Higher Education Research and Development, 18: 57-75.

Biggs, J. and C. Tang 2011 Teaching for Quality Learning at University: What the Student Does $\left(4^{\text {th }}\right.$ ed. $)$, Maidenhead: SRHE and Open University Press.

Black, P. and D. William 1998 Inside the Black Box: Raising Standards Through Classroom Assessment, London: NFER Nelson.

Bridges, P., Cooper, A., Evanson, P., Haines, C., Jenkins, D., Scurry, D., Woolf, H. and M. Yorke, 2002 Coursework marks high, examination marks low: discuss, Assessment and Evaluation in Higher Education, 27: 35-48.

Brown, G., Bull, J. and M. Pendlebury 1997 Assessing Student Learning in Higher Education, London: Routledge.

Chen, J. and T. Line 2012 Do Supplemental Online Recorded Lectures Help Students Learn Microeconomics? International Review of Economics Education, 11: 6-15.

Cohen, S. 1987 Instructional Alignment: Searching for a Magic Bullet, Educational Researcher, 16: 16-20.

Cooper, N. 2000 Facilitating Learning from Formative Feedback in Level 3 Assessment, Assessment and Evaluation in Higher Education, 25: 279-291.

Forsythe, F. 2002 Problem-based Learning, in The Handbook for Economics Lecturers: Teaching. Accessed 25 April 2015. http://www.economicsnetwork.ac.uk/handbook/.

Gibbs, G. and C. Simpson 2004 Conditions under Which Assessment Supports Students' Learning, Learning and Teaching in Higher Education, 1: 3-31. 
Healey, M. and A. Jenkins 2000 Kolb's Experiential Learning Theory and its Application in Geography in Higher Education, Journal of Geography, 99: 185-195.

Killen, R. 2007 Effective Teaching Strategies: Lessons from Research and Practice, South Melbourne: Thomson Social Science Press.

Kolb, A. and D. Kolb 2005 Learning Styles and Learning Spaces: Enhancing Experiential Learning in Higher Education, Academy of Management, Learning and Education, 4: 193-212.

Marton, F. and R. Säljö 1976 On Qualitative Differences in Learning. Outcome and Processes, British Journal of Educational Psychology, 46: 4-11.

Nicol, D. and D. Macfarlane-Dick 2006 Formative Assessment and Self-regulated Learning: a Model and Seven Principles of Good Feedback, Studies in Higher Education, 31: 199-218.

Ramsden, P. 1992 Learning to Teach in Higher Education, London: Routledge.

Roach, T. 2014 Student Perceptions towards Flipped Learning: New Methods to Increase Interaction and Active Learning in Economics, International Review of Economics Education, 17: 74-84.

Szili, G. and J. Sobels 2011 Reflections on the Efficacy of a Constructivist Approach to Teaching and Learning in a First-year Bachelor of Environmental Management Topic, Journal of Geography in Higher Education, 35: 499-512.

Trigwell, K. and M. Prosser 2014 Qualitative Variation in Constructive Alignment in Curriculum Design, Higher Education, 67: 141-154.

Tsigaris, P. 2008 Is There a Double Dividend from Classroom Experimental Games? American Journal of Business Education, 1: 23-36.

Tynjala, P. 1998 Traditional Studying for Examination vs Constructivist Learning Tasks: Do Learning Outcomes Differ? Studies in Higher Education, 23, 2: 173-189.

Van Wyk, M. and G. Alexander 2010 Do Teaching Methods Presented by the National Council on Economics Education (USA) Enhance Trainers' Learning Capacity in Economics Education? A South African perspective, Journal of Social Sciences, 23:159-169.

Walsh, A. 2007 An Exploration of Biggs' Constructive Alignment in the Context of Workbased Learning, Assessment and Evaluation in Higher Education, 32:79-87.

Wilson, D. and W. Dixon 2009 Performing Economics: A Critique of 'Teaching and Learning', International Review of Economics Education, 8: 91-105. 